\title{
A mixed methods approach to the social assessment of transport infrastructure projects
}

\author{
Karen Lucas $^{1}$ (D) $\cdot$ Ian Philips $^{2} \cdot$ Ersilia Verlinghieri $^{3}$
}

Accepted: 20 January 2021 / Published online: 17 February 2021

(c) The Author(s) 2021

\begin{abstract}
In this paper, we propose a mixed methods quantitative and qualitative approach to capture fully the measurable and less tangible social impacts of transport projects on local people and communities. The approach was used to assess the potential social impacts of a strategic road by-pass project case study in a deprived region of Wales in the UK. The project specifically aimed to stimulate local economic growth and regeneration in the local areas it serves. In a 'before and after' case study, we combined fine-grained, GIS-based spatial analysis of secondary datasets with qualitative participative exercises with the local residents of the five communities living adjacent to the road, and interviews with professional local stakeholders. This mixed methods approach significantly enhanced understanding of both the social benefits and disbenefits of the road project. It helped to reveal local concerns that would not otherwise have been apparent from secondary dataset analysis alone. The qualitative studies were also successful in bringing to the table new 'hard to reach' voices that had not been heard through the formal consultation and public engagement process. The study revealed that the social benefits accruing to local people from the project could have been significantly enhanced, whilst a number of its locally occurring negative social impacts could have been avoided had social assessment been employed earlier in the decision processes concerning its routing and design. Recommendations to improve the practice and uptake of social assessments at the option appraisal, project design mitigation and post evaluation stages of transport projects are included in the paper.
\end{abstract}

Keywords Transport projects · Social impact assessment $\cdot$ Case study $\cdot$ Communities . Practitioners

Karen Lucas

karen.lucas@manchester.ac.uk

1 School of Environment, Education and Development, University of Manchester, Manchester, UK

2 Institute for Transport Studies, University of Leeds, Leeds LS2 9JT, UK

3 Transport Studies Unit, University of Oxford, Oxford OX13QY, UK 


\section{Introduction}

Despite increasing efforts within research and policy circles to understand the social and health implications of transport interventions and policies, measurement and assessment of them in practice is extremely limited. Also, social impacts are generally given lesser importance than economic and environmental impacts within the appraisal process (Jones and Lucas, 2012; Mottee et al., 2020). On the other hand it could be argued that the marginalisation of social assessments is because of the lack of political value that is placed upon them, and therefore an unwillingness to dedicate much in the way of resources to them during the commissioning process.

Social impacts generally refer to how major transport investments practically affect people's lives, both positively (social benefits) and negatively (human burdens). Distributional impacts means: the different ways in which the social impacts of transport affect various groups within society (Markovich and Lucas 2011: 9), and refer to which population segments are affected, how, when, in which places and over what durations of exposure. In the UK, social and distributional impacts (SDI) appraisal is part of the overall transport appraisal toolkit but is only a requirement for major road schemes costing over $£ 10$ million (Department for Transport 2018-TAG Units 4.1 and 4.2). It is also a 'desk based' methodology, so it remains an open question as to whether the outputs of these analyses are sufficient for decision-makers to fully assess social and distributional impacts of new transport interventions. In particular, the questions of precisely who benefits and/or disbenefits from different types of projects and project options, how, where and to what extent they are affected is largely absent from the decision process.

This paper describes a mixed methods quantitative and qualitative approach to social assessment, which was tested in an applied 'before and after' opening case study of an interurban road project in South Wales, UK. The Welsh Government commissioned the study to gain a better understanding of the wider social effects of road investments to inform their future policy and investment decisions. The study aimed to capture more fully the measureable and less tangible social impacts of transport projects on people and communities living along the route. The key issues the paper considers are:

(i) What currently constitutes a 'best practice' SDI assessment in the transport context?

(ii) What new insights can be gained using a mixed methods approach, and what are the lessons learned for methodology from its practical implementation?

(iii) How can the practice of social assessment in the transport domain be enhanced in the light of our research?

In the concluding sections of the paper, we also discuss some of the pros and cons of our mixed methods approach and make some recommendations for the improvement of future practice. Although the study is UK-focused, it offers many useful insights for researchers and practitioners who are grappling with issues of social justice in the field of transport in other national, regional and local contexts. 


\section{Background}

The economic dimension of transport appraisal remains dominant at all levels of UK policy decision-making (as in many other countries) and both economic and environmental impact assessments have been the subject of extensive academic research in recent years. In contrast, despite a growing body of literature addressing the links between transport interventions and issues of social equity and justice (Grengs 2005; Golub and Martens 2014; 2019; Sheller Sheller 2018; Verlinghieri and Schwanen 2020), there is still a very limited literature proposing methodologies that are able to capture and assess the social and equity dimensions of transport investments projects (Jones and Lucas 2012; Geurs et al. 2012). Within environmental impact assessment (EIA), there has been an allied struggle to incorporate aspects of social justice (Lucas and Pangbourne, 2014; Motte et al., 2018; 2020; Walker 2010), which is a trend that has also emerged in other sectors, such as energy infrastructure (Fell et al 2019). This is despite the widespread policy claims new transport investments can potentially generate significant additional social benefits (e.g. Department of Transport 2018; Shropshire Council 2015; Welsh Government 2017).

The UK's appraisal approach reflects the main political reason for public investment in the transport system, which continues to be predominantly focused on stimulating economic growth through large infrastructure projects (e.g. Northern Powerhouse, 2019). The economic benefits of such projects are frequently overstated in the ex-ante appraisal process, which is partly due to overly-optimistic forecasting, and also because project costs often exceed their initial forecasts (Flyvberg 2014; Davies et al. 2018). From the constructor's point of view there is a further problem that a project success is defined purely in terms of its 'on-budget' and 'on-time' delivery (Flyvbjerg, 2014), which further discourages thinking about their potentially negative social impacts on local communities. In light of increasing public concerns about their consequences for health and wellbeing, health impact assessments (HIA) are often used in an attempt to overcome this shortfall (e.g. Transport for London 2015).

Multiple HIAs have confirmed that the dominant economic perspective in traditional transport appraisal tends to downplay the negative social impacts of large transport infrastructure projects on local communities (Nieuwenhuijsen et al. 2017). They can also demonstrate the superior social value of much smaller and contextually-sensitive interventions to remove traffic nuisances and public realm projects to improve walking and cycling conditions. However, such studies are most often qualitative in their approach and can become lost, buried or undervalued and marginalised within the wider and largely monetised project appraisal process. They also usually do not happen early enough in the decision process to successfully affect routing options or project design and so are reduced to minor mitigation and compensation measures late in the project delivery stages. A further weakness is that many social assessments involve only the professional stakeholders in the local area and do not fully engage with local communities themselves.

We developed this study to specifically address some of these methodological issues. In doing so, we also recognised that numerous social assessment frameworks have previously been developed internationally to address the unintended consequences of different development projects. Most adopt a strong human-rights focus, specifically to highlight their detrimental social effects (e.g. Vanclay et al. 2015). The International Association for Impact Assessment (IAIA) state that social impacts should include all the issues associated 
with a planned intervention (i.e. a project) that affect or concern people, whether directly or indirectly. Specifically, a social impact is:

..something that is experienced or felt in either a perceptual (cognitive) or a corporeal (bodily, physical) sense, at any level, for example at the level of an individual person, an economic unit (family/household), a social group (circle of friends), a workplace (a company or government agency), or by community/society generally. These different levels are affected in different ways by an impact or impact causing an action. (ibid: 2).

This approach to social assessment tries to overcome the limits of the mechanistic understandings of impacts in technocratic approaches to consider instead the multiple value systems and complexities that shape people's perceptions (Aledo-Tur and Domínguez-Gómez 2017). Impacts are subjectively perceived, and as such, are to be considered valid as long as they are felt to be shaping the lives of various social actors. Similarly, 'the identification of impacts always depends on the context and the constantly shifting positions of the actors and their social praxis' (ibid: 59). To capture this, practitioners have developed tools and methods for impact assessment that are calibrated to the specific contextual situation, with the use of techniques such as social mapping and socio-economic survey (Antonson and Levin 2018). These exercises are designed to carefully mediate the complexities of highly localised social activities and interactions and the full diversity of various value-driven perspectives.

Geurs et al. (2012: 71) provide a useful starting point to frame social impacts in the transport context, defining them as:

... changes in transport sources that (might) positively or negatively influence the preferences, well-being, behaviour or perception of individuals, groups, social categories and society in general (in the future). Here, transport sources are defined as a movement and/or (potential) presence of vehicles using infrastructure or merely the presence of infrastructure itself.

The authors also provide a useful source-effect-impact-receptor chain framework across five key dimensions of the social impacts in transport, whereby the physical effects of the system might generate effects in terms of behaviours, attitudes and preferences across different social groups, which can subsequently lead to social injustice effects that require policy interventions to correct (see Table 1). This causal framework provides a starting point for the development of indicators and metrics with which to appraise the broad social effects of new transport infrastructures or policies to bring them broadly in line with the quantified methodologies for economic and environmental impact appraisal.

Effective social assessments have a clear framework for 'success' and project purpose that have to be defined in advance of implementation including all the stakeholders potentially affected (Vanclay et al. 2015). Best practice approaches recommend that social assessments should be carried out at each phase of the decision making process, from project inception to design, during its construction and operational phases (as shown in Fig. 1).

Good practice in social assessment case studies have also utilised a variety of participatory research methods with local communities and professional stakeholders to deliver an ongoing process of engagement (Mottee and Howitt 2018; Mottee et al 2020). These recommended participatory approaches are largely missing in the $\mathrm{UK}$, where the social assessments of transport projects is most commonly based upon 
Table 1 From Geurs et al. 2012: 75

\begin{tabular}{lll}
\hline Theme & Sub-themes & Impact \\
\hline Presence of infrastructure & Structurally & Visual quality \\
& Temporarily (construction) & Historical/cultural resources \\
& & Severance/social cohesion \\
& & Noise nuisance Barriers and diversions \\
Presence of parked vehicles & & Uncertainty of construction \\
& & Forced relocation \\
Presence of transport facilities, & Transport facilities & Visual quality \\
services and activities & & Use of space \\
& & Availability and physical access \\
& & Level of service provided \\
Traffic (movement of vehicles) & Land use Safety & Transportation choice/option \\
& & values \\
& & Cultural diversity \\
& & Access to spatially distributed \\
Travel (movement of people) & services and activities \\
& & Accidents \\
& & Averting behavior \\
& & Safety perceptions \\
& & Public safety (dangerous cargo) \\
& & Noise levels, nuisance \\
& & Soil, air and water quality \\
& & Intrinsic value, journey quality \\
& & Physical fitness \\
& & Security \\
& &
\end{tabular}

quantitative GIS (Geographic Information Systems/Science) analysis of secondary public datasets. There is no mandatory requirement for any additional local surveys or public engagement to be carried out (Department for Transport 2018). As such, the UK government's recommended approach is unable to capture a full spectrum of social impacts (both negative and positive) or identify who is affected by them, as we later discuss.

\section{Methods $^{1}$}

The social assessment approach we developed for our case study, as it is described in this paper, was purposefully constructed to address some of the shortfalls in current practices that we have identified above. It first sourced a large number of publicly available and government-held datasets to undertake a fine-grained, GIS-based, quantitative analysis of the project's social impacts on proximal communities. This analysis was then combined with qualitative fieldwork studies, including local area 'foot surveys', two group discussions and ten in-depth interviews with local professional stakeholders and twelve focus groups (six before and six after the road opened) with residents in five communities proximal to the

\footnotetext{
1 For a detailed explanation of our methodology see also https://environment.leeds.ac.uk/download/downl oads/id/5083/methodological_annex.pdf
} 


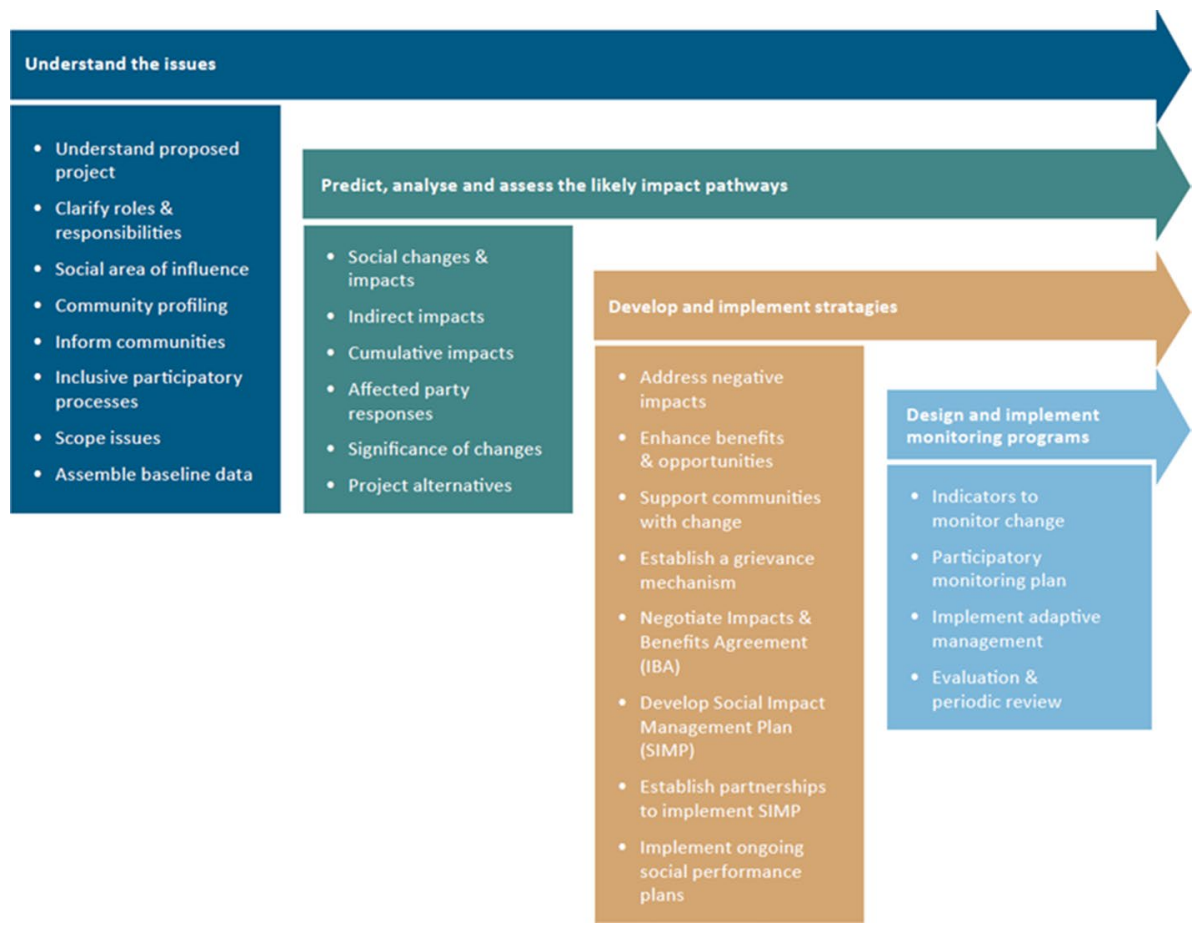

Fig. 1 The phases of social impact assessment, SourceVanclay et al. 2015: 7

road and students from a local school). The qualitative studies sought to gain a more situated understanding of people's local travel behaviours and activity needs and their perceptions of and attitudes to the project before and after its opening.

The road we assessed is the A465 By-Pass project, which links between West Wales and the Midlands and the South Wales Valleys with a stated intention to support the regeneration of the communities it serves. Construction of Sect. 3 started on site in January 2013 and was completed in autumn 2015. The bypass was officially opened in September 2015. At the post-opening field stage of our study (19th-23rd October) there were still some continuing road works and lane closures along parts of Sect. 3, as well as those associated with the de-trunking works on parts of the old A465, when. There were also road works on the adjacent Sect. 2 as work had started on upgrading this section of the A465.

Our social assessment specifically focuses on the $7.8 \mathrm{kms}$ stretch of the road that passes through five local communities (Fig. 2).

The high-level project objectives for the A465 project were: (a) to improve journey times and road safety; (b) to reduce road traffic-related death and causalities; and (c) to facilitate local economic regeneration of the surrounding communities. The project design also included enhancement of the National Cycle Route 46 and a segregated new cycleway alongside the new road and at a local business park. Pedestrian controlled 


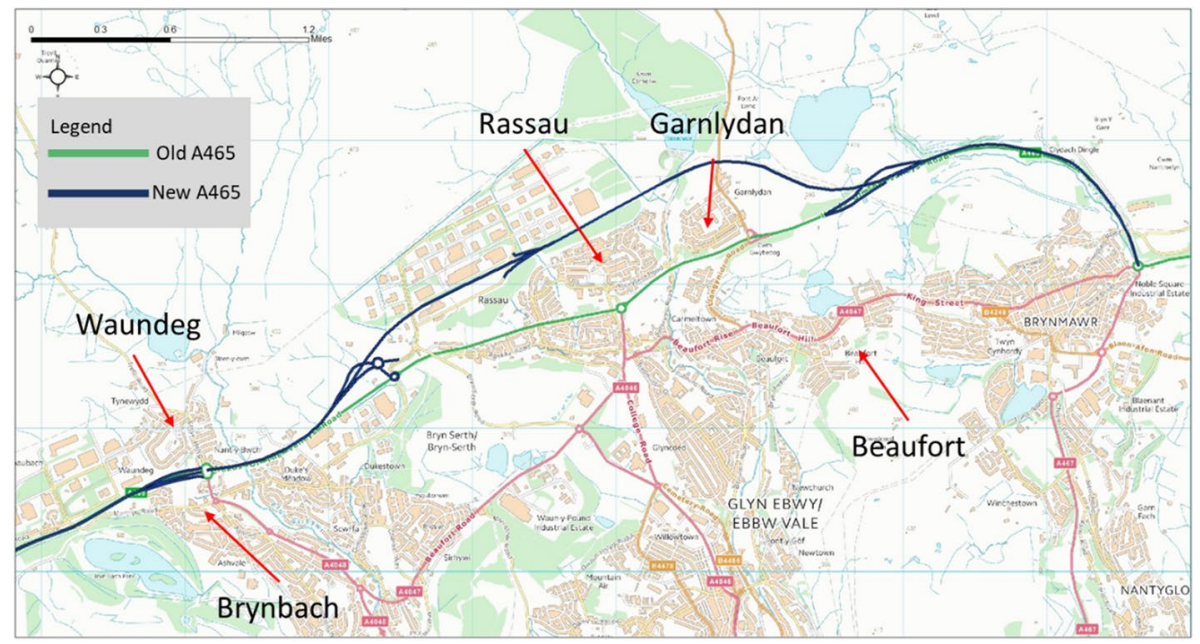

Fig. 2 The study area showing the five affected local communities alongside the road. Source Backdrop map Ordnance survey accessed via Edina Digimap 2015. Road Alignment data provided by Welsh Government (the segrated cycleway follows the line of the new road). Further detail on local cycle routes are shown non supplementary interactive maps at: https://github.com/DrIanPhilips/Social_and_Distributional_ Impacts_A465/blob/master/A465_old_new_wimdQuintile_cycleway.html

traffic lights were introduced at the Waundeg two-grade roundabout following local community complaints about walking severance to the local school.

The social assessment involved four distinct but iterative stages (see Fig. 3 for an overview of the entire assessment process).

Stage 1 began by defining the geographical extent of the project. As the appraisal intended to measure the local SDI (rather than regional strategic impacts) of the study area. An approximate polygon of local trips was drawn to identify the local catchment for the study area, firstly using Google maps directions to visualize travel in the vicinity of the road scheme being assessed, and secondly the Datashine commute ${ }^{2}$ census commute flow visualization tool. The Lower Super Output Areas (LSOAs) from the 2011 Census falling within this polygon were then used to identify the population profile of the study area according to some key social and demographic attributes-principally using the UK Census and the Welsh Index of Multiple Deprivation and other secondary datasets. The scope of the spatial analysis was limited to descriptive visualization that which could reasonably be performed with desktop GIS (e.g. ArcGIS, QGIS) and did not require specialist geo-computational skills or big data/high performance computing systems. The rationale for such an approach was for the purposes of easy replication. Local governments in the UK operates in a highly resource constrained environment and lack the staffing and skills to produce complex modelled analyses (Wong et al, 2015; Riddlell et al. 2012).

These quantitative datasets were useful to develop a background social profile of the study area and to map broadly how different communities and their residents might be affected by the measurable social impacts of the new road bypass. However, it was

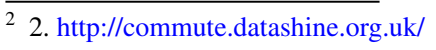




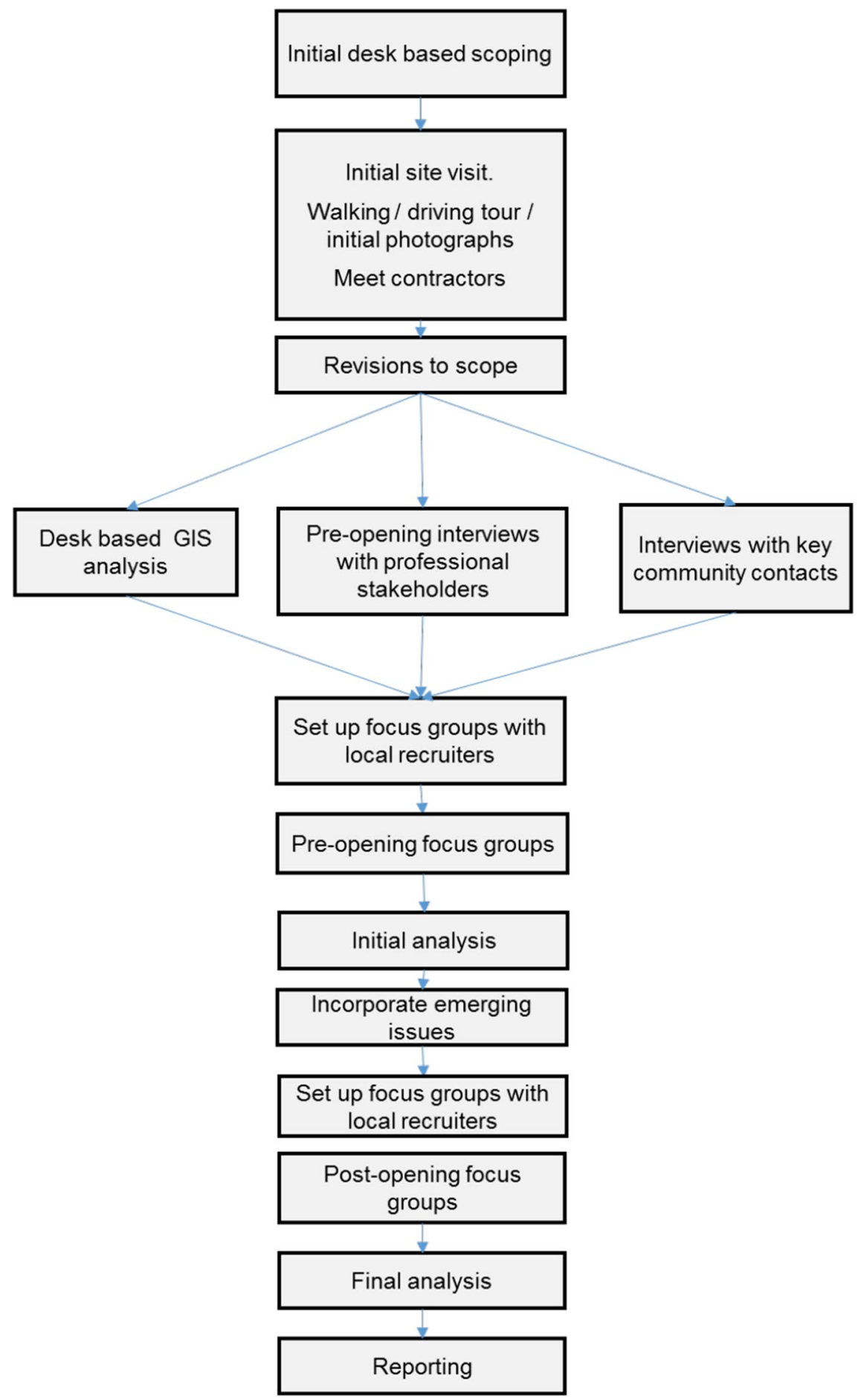

Fig. 3 Overview of the social assessment process. Source: Authors' own contribution. (Color figure online) 
Table 2 Profile of focus group attendees

\begin{tabular}{lllll}
\hline Location of group meetings & Target population & Age range & $\begin{array}{l}\text { Number in } \\
\text { groups (1 } \\
\text { and 2) }\end{array}$ & Male/female split \\
\hline Garlydan Football club & Working males & $18-65$ & 86 & $100 \%$ male \\
Rassau community centre & Social housing residents & $30-65$ & 68 & $40 / 60$ \\
Beaufort & Local home owners & $45-65$ & 45 & $80 / 20$ \\
Waundeg & Social housing residents & $18-65$ & 85 & $35 / 65$ \\
Bryn Bach Primary School & Parents & $35-55$ & 64 & $100 \%$ female \\
Brynmawr secondary school & School students & $14-16$ & $18 \mathrm{n} / \mathrm{a}$ & $50 / 50$ \\
\hline
\end{tabular}

necessary to collect some further primary data about local residents' actual travel and activity patterns and location choices, as well as their perceptions of and attitudes towards the project, which could not be determined through these quantitative analyses. Although an extensive survey would have been an optimal choice to have a precise picture of travel and activity patterns, due to the limited resources, we decided to prioritise a more in depth understanding of local residents' perceptions and needs with a series of community focus groups that we carried out in stage 2 .

Stage 2 involved a series of community-based qualitative fieldwork exercises with local residents. The aim here was to complement the desk-based quantitative analysis, as well as to test its reliability and validity. Initially two field visits were used to familiarise the research team with the local area. Observational 'foot surveys' were undertaken, to collect photographic evidence. Two group discussions of the project and its intended delivery objectives were held with the Welsh Government and the Blaenau Gwent District Council, involving a range of transport and land use planners, regeneration officers and other relevant policy officers such as education and housing. Ten individual professional interviews were undertaken with more locally active stakeholders (e.g. the community liaison officer for the project developer, primary and high school headteachers, local council members, community group representatives). These interviews were largely to gather contextual information about the local area, the road scheme, public transport and local activities in the area and to assist with recruitment of local residents for the focus groups exercises.

Stages 3 and 4 involved a series of eleven focus groups with local residents in the five communities either side of the road; six were conducted three months before the road opening and five with the same participants one month after its opening. The participants were recruited through the local gatekeepers from the stage 2 interviews and the Public Liaison Officer from Carillion (the contractor), who had regular contact with community members. We specifically targeted at perceived 'hard to reach' individuals who were perceived to be overlooked by the ongoing community engagement process. There was no intention to be representative in the sample, as this was a strictly qualitative study aiming to add depth to desk-based quantitative analysis, but we did seek a range of views from the perspectives of age, gender and social circumstances. In total, 32 adults took part in the five community focus groups and 18 Year 10 students at the school (see Table 2).

During the focus group we asked the participants to comment upon their own perceptions of the different impacts of the road, as well as their personal experiences of the engagement process that had accompanied the design and construction stage of the scheme with a particular focus on: (a) the new road and cycleway, and (b) the old by-passed road. 


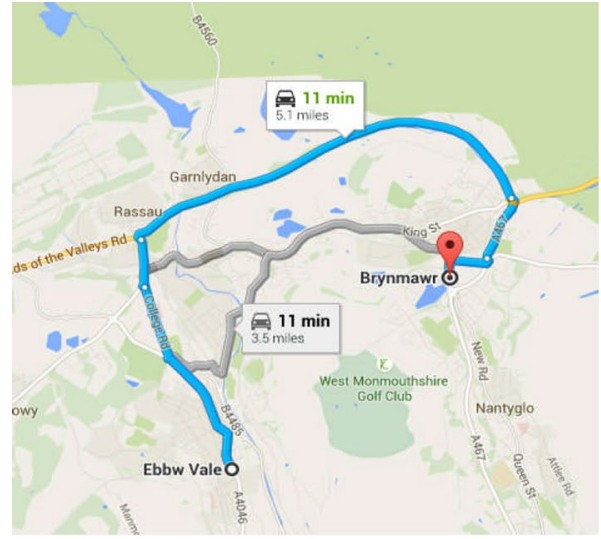

Recommended route 5.1 miles, 11 minutes. Use Old A465. Accessed May 2015

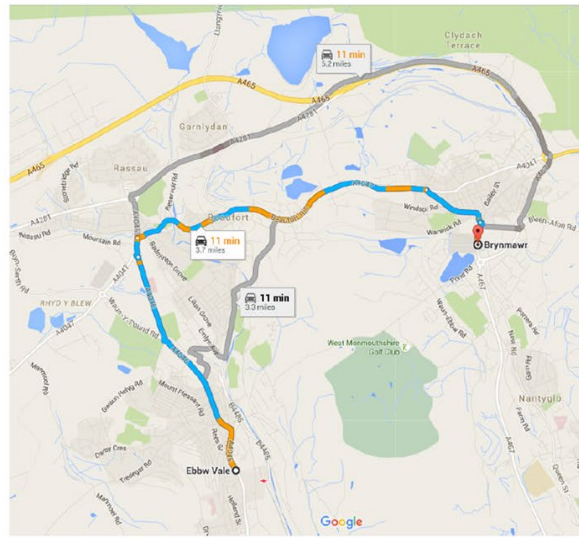

Recommended route: 3.7 miles, 11 minutes Use A4047 Accessed December 2015

Fig. 4 The same google maps directions query was run before Sect. 3 opened and after. After opening of Sect. 3 the recommended route uses the A4047 rather than Sect. 3. source https://environment.leeds.ac.uk/ download/downloads/id/5081/social_assessment_report.pdf Fig. 6 p30

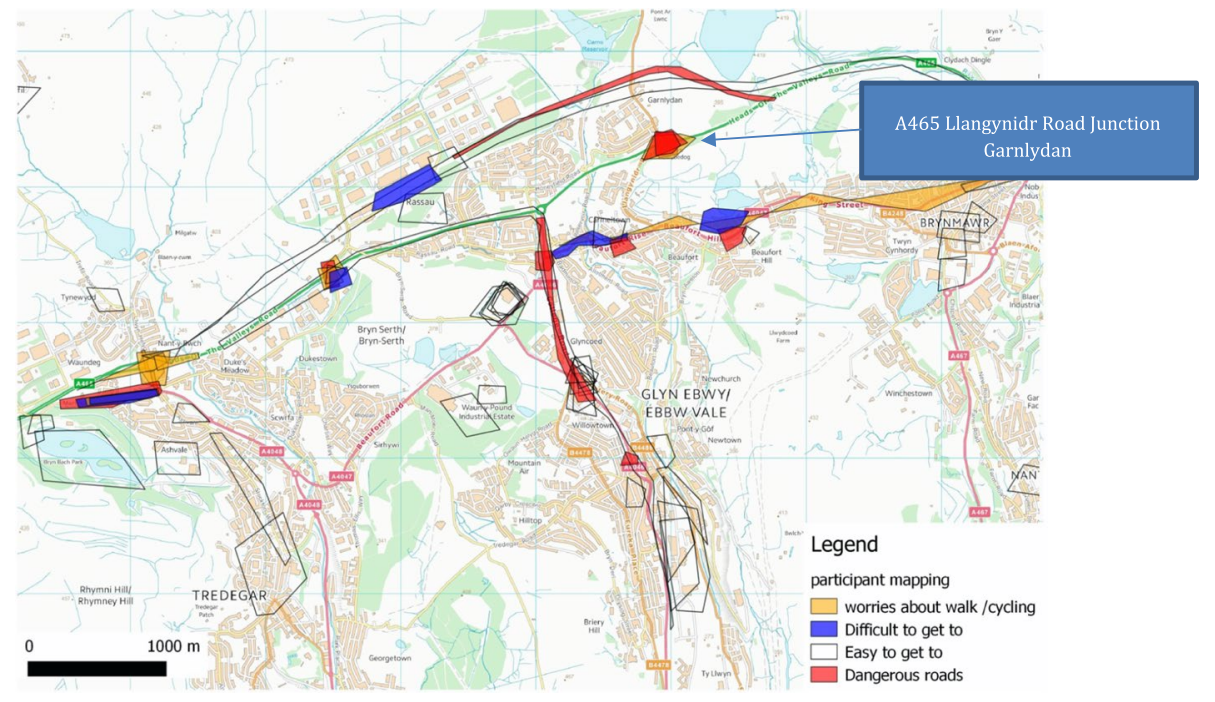

Fig. 5 Locations marked by participants in post opening focus groups. Source: Authors' own contribution

Participants also collectively produced a map of their activity destinations and means of accessing them (walk, cycle, car, public transport, etc.), marking where they perceived walking and cycling to be dangerous, (an example is reproduced in Figs. 4, 5). The aim of these exercises was to complement and deepen the interpretation of the desk-based analyses, and also to gain richer understandings of how local people lived, worked, travelled, and carried out their daily activities, as well as to find out what they most valued about their home locations. 
Table 3 Scoping the impacts on resident population groups in the A465 case study. Source adapted from TAG Unit 4.2, Department for Transport, 2018

\begin{tabular}{|c|c|c|c|c|c|c|c|}
\hline \multicolumn{2}{|c|}{$\begin{array}{l}\text { Special interest person groups vs } \\
\text { impact domains }\end{array}$} & 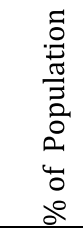 & 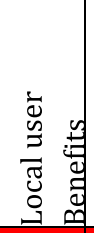 & 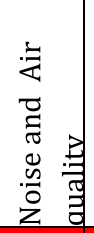 & $\frac{\mathscr{n}}{\stackrel{d}{0}}$ & 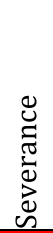 & 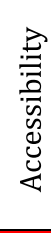 \\
\hline \multirow{12}{*}{$\begin{array}{l}\text { Resident } \\
\text { population in } \\
\text { the impact } \\
\text { area }\end{array}$} & \multirow{5}{*}{$\begin{array}{l}\text { WIMD } \\
\text { quintiles }\end{array}$} & $45 \%$ & & & & & \\
\hline & & $20 \%$ & & & & & \\
\hline & & $21 \%$ & & & & & \\
\hline & & $13 \%$ & & & & & \\
\hline & & 0 & & & & & \\
\hline & Children $(<16)$ & $18 \%$ & & & & & \\
\hline & $\begin{array}{l}\text { Young people (16- } \\
24)\end{array}$ & $12 \%$ & & & & & \\
\hline & Older people $(>65)$ & $19 \%$ & & & & & \\
\hline & $\begin{array}{l}\text { People with a } \\
\text { disability }\end{array}$ & $16 \%$ & & & & & \\
\hline & $\begin{array}{l}\text { Black Minority } \\
\text { Ethnic }\end{array}$ & 0 & & & & & \\
\hline & No car households & $28 \%$ & & & & & \\
\hline & $\begin{array}{l}\text { Households } \\
\text { dependent childre }\end{array}$ & $29 \%$ & & & & & \\
\hline
\end{tabular}

Colour Key: Grey = not applicable, Red=expected disbenefit, Green = expected benefits, Amber $=$ benefits unclear. Note that impacts are not eliminated at this stage, emerging issues can be included if evidence of local impacts are observed during fieldwork and further analysis.

The focus group fieldwork data was transcribed verbatim and thematically analysed alongside researchers' notes according to the six key areas of social impact identified at the stage 1 GIS-analysis. The qualitative data was then used to interrogate the validity of the quantitative analysis at a much finer spatial scale and also to add more contextual detail to the overall assessment of the social impacts of the road. 


\section{Discussion of results and key findings}

This next section of the paper offers an overview of the new insights about the social impacts of the case study project and their consequences for people living in the area. Six key themes of social impact were identified during the stage 1 GIS-analysis as having potential local impacts on communities with potentially differential outcomes across the social groups living in the area. These have been complemented with other themes, which emerged from the focus groups and interviews. The combined quantitative and qualitative findings are presented below and summarized in Table $3 .^{3}$

\section{Local user benefits}

The traffic network model for the earlier economic appraisal of the project was not available to use, it was therefore difficult to corroborate with any degree of accuracy the extent to which local residents would benefit from direct use of the new road through the social assessment. Car ownership is low across the study area but particularly within the lower income households (the majority of the catchment population), suggesting that most noncar owning households would not gain any benefits from the new road in this respect. Basic route planning from our six communities to locations the local towns (Ebbw Vale, Tredegar) suggested routing, which did not make use of the A465 upgrade. The design and layout of the slip roads required circuitous route on 'B' roads onto the new A465, which would lengthen their journey times. This would suggested that local people would not be the main users of the new road but might benefit from quicker journey times on the old A465 as a result of the removal of heavy traffic (see Fig. 5).

Participants also said that most local residents, especially those without access to cars, would not gain any significant user benefits from the new infrastructure.

"Generally people from Ebbw Vale and Beaufort and all who are not working, which is as you know we're in a deprived borough, there are a lot of those people who perhaps don't own cars ... I don't think it's would have any difference to them at all in their lives [...] think it will have little impact on Blaenau Gwent as a community. The elderly, young children or you're talking about the general community, I don't think any of them will have noticed there's much different, other than perhaps traffic will pass their front doors those that live on the main road" (Beaufort FG2, October, 2015).

This local perception seems reasonable, as the A465 is a strategic route and not designed for local trip making. Furthermore, three of the local neighbourhoods do not have a slip road to take them directly onto the new road, making the remaining de-trunked old road of greater utility to them.

\footnotetext{
3 We have aggregated the discussion around affordability and accessibility, due to the limited mention of affordability in the qualitative data.
} 


\section{Noise and air pollution}

Noise and air pollution were assessed and mapped as part of the original EIA and reported in the original Environmental Statement (Welsh Government 2012). Parts of the Rassau and Garnlydan communities were forecast to have major beneficial noise impacts and other parts some adverse noise impacts, with disbenefits moving from the southern to the northern parts of these neighbourhoods. It was also concluded that there would be an overall increase in emissions due to increased vehicle kilometres.

Some noise mitigation measures were introduced in response to this assessment and residents in the two focus groups for these study areas found the new A465 road to be quieter than they had expected. Some people even commented that the noise from Rassau industrial estate was greater than the noise from the new road, which may be due to the selection of quieter surfacing materials on the new road. Participants notably did not discuss issues of air quality, but here was a general sense that the new road would not be any worse than the old road.

However, the forecast changes in air quality suggest that 3000 people in the most deprived quintile of the Welsh Index of Multiple Deprivation (WMID) are at risk of worsening air quality, compared with 1473 people in quintiles, 282 people in quintile 3, and none in quintile 4 . This demonstrates a definite inequity in the distribution of these disbenefits in terms of income. In the Rassau community in particularly, considerable air quality deterioration was forecast for the poorer residents living in social housing to the north of the study area whereas the more affluent new owner occupier households in the south of the area were forecast air quality improvement. These displacement effects have the potential to negatively affect the level of people's exposures to traffic-related air pollutants, with implications for their health (Khreis et al. 2016). Despite being in a semi-rural area on the edge of a national park, there may still be some dispersal issues.

\section{Accidents (road deaths and casualties)}

A third forecast benefit identified in the ex-ante appraisal was the reduction of road deaths and casualties (referred to as "accidents" in TAG) on what has been a dangerous stretch of non-dualled road, making vehicle overtaking a high risk problem. The users of the new section of the A465 are forecast to benefit from the latest road safety standards. Users of the old A465 could also benefit from a reduction in the number and severity of accidents, if a lower speed limit is enforced and the de-trunking of the road provides the opportunity to include more safety features by design. However, the local district council reported they had no plans to reduce speeds on the old road below 50 miles per hour, which would be too fast to introduce such features.

Within the focus groups, the reduction in car collisions was seen as one of the greatest anticipated benefits of Sect. 3, with several participants referring to particular accident black spots such as the old A465 Llangynidr Road Junction at Garnlydan (see Fig. 5). However, participants expressed concern at the design and retention of the 50mph speed limit on the old A465, which they felt should be reduced to $30 \mathrm{mph}$, in line with other local roads. Some of the perceived danger areas for walking and cycling that paricipants highlighted were related to the design of Sect. 3, while others related to localised changes in traffic movements resulting from the construction works and/or detrunking of the old road (see Fig. 5). 


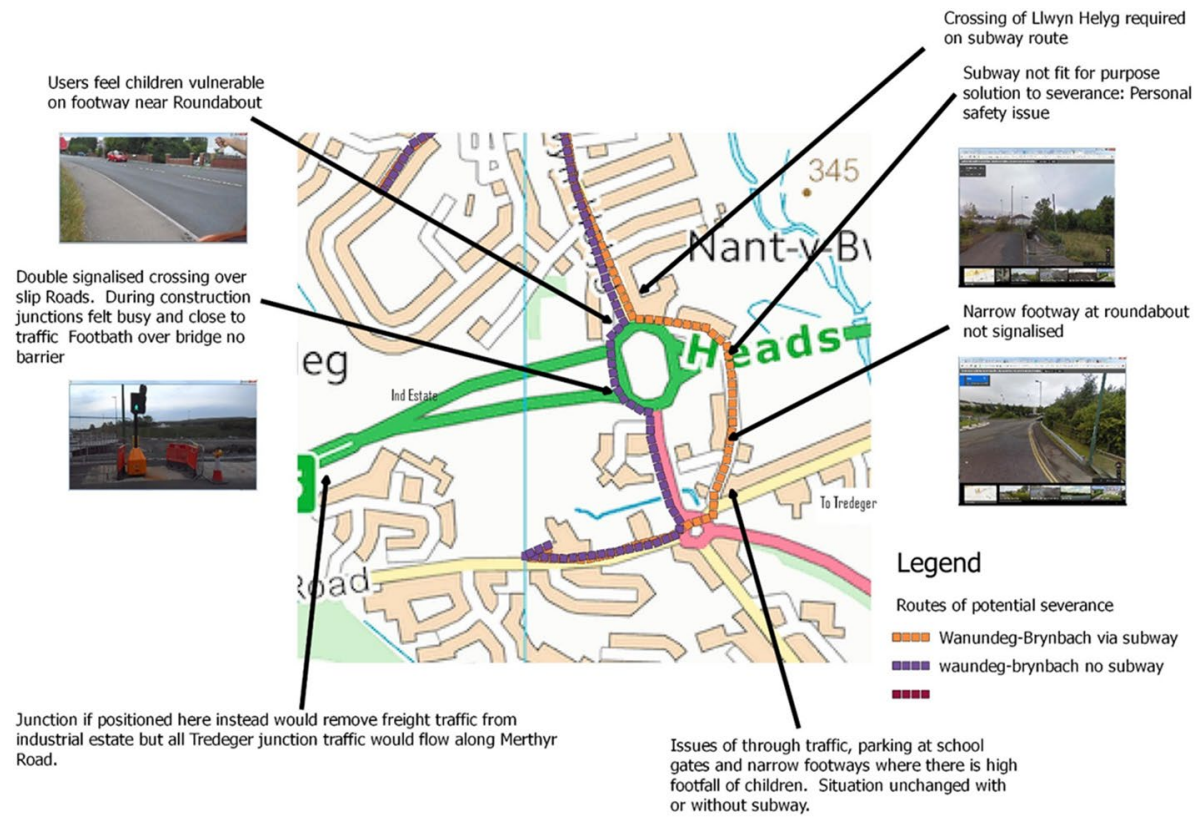

Fig. 6 Map of the community severance impacts of the Waundeg roundabout. Source: Authors' own contribution

\section{Severance}

Severance in our analysis refers to pedestrian connectivity with key destinations, such as local schools and shops, which was measured in GIS by calculating the changes in pedestrian walk distances from the home location to these destinations based on the footpath network. Perceptions of community severance were also recorded in the focus groups through the participatory mapping exercise. Our analysis identified that people's perception of severance had significantly increased since the closure of the old A465 for de-trunking works. In particular, participants from Tredegar said they felt "cut off" or "ostracised". Rassau residents also perceive increased severance and inability to access the town centre on foot.

One particularly severe incidence of community severance that arose was the increased dangers of walking to the local primary school for people living on the Waundeg social housing estate (Fig. 6). Residents of this estate experience high levels of deprivation and a large percentage of households do not own cars, and so are more dependent on walking. Although, the new grade-separated walking route is physically shorter than the old walking route (shown in orange in Fig. 6), the qualitative study identified that that pedestrian crossing is perceived as much more dangerous by parents taking their children to school. This means that the severance issue caused by the road is far greater than the quantitative desk-based analysis had identified.

By highlighting this problem, which would not have been picked up without a mixed methods approach, our social assessment was able to engage with policymakers about possible mitigation measures, with the effect that a dedicated school bus now runs the children to and from the school. Had a qualitative social assessment been undertaken prior to construction of the new road, then more permanent alternative solutions could have been 
introduced in the project design, such as the introduction of a walking and cycling bridge from the housing estate to the school.

\section{Accessibility}

In the original project appraisal, consultants undertook analysis of the accessibility impacts of the whole of the A465 project (Welsh Government 2012). Access to employment was forecast to increase by over 20 percent in the study area between 2010 and 2030 and access time to the hospital would decrease by 4-6 min. The most notable accessibility improvements would be to for car drivers the strategic employment centres in the nearby cities of Swansea and Abergavenny. The mapped outputs from these analyses were made available for our social assessment, but neither the raw data or the original software modelling tool were available to corroborate them.

In the qualitative study, participants were asked to identify which areas they considered were easy or difficult places to access in the participatory mapping exercise (see Fig. 5). It is notable that the Rassau industrial estate was seen as particularly difficult to access, suggesting problems of access to local employment for these residents. The evidence also suggests that residents would tend to continue to the old A465 and other local roads for local trips in preference to Sect. 3, as suggested by the shorter journey times for these routes in the Google maps analysis (see Fig. 4). This suggests that although strategic car-based accessibility to major centres such as Swansea, Abergavenny and Merthyr Tydfil will be significantly improved, local accessibility remains largely unaffected by the new road.

Although public transport improvements were not a part of the A465 project, in the focus groups, serious concerns were raised in the focus groups about the reliability, frequency and cost of local public transport services (and a subsequent need to use taxis, especially at night), and of car dependence because of this. For example from Princetown, a bus journey to Merthyr would require:

"You would catch the bus that comes from Tredegar to Rhymney Railway Station, you'd get off that on Rhymney Bridge then you'd either have to hope that you'd catch the connecting bus which you usually wouldn't, then you're waiting another about twenty minutes to catch a bus to Merthyr and same on the way back. Usually it's quicker to walk from Rhymney Bridge to Princetown than wait for the bus" (Bryn Bach FG1).

As a general rule, there is poor integration of public transport service improvements with new road infrastructure projects, partly because different layers of government are responsible for highways and local transport and partly due to the deregulation of bus services in the UK context.

Participants also commented on the new cycle infrastructures, with mixed responses. For example, a mother of three commented on the difficulties she experienced to access the cycle lane:

"I wouldn't walk out my door and ... head to this cycle lane with the children and I've got to go over the Heads of Valley with three kids on bikes it's just impossible, I mean I'd have to drive them and then get out [to use it]" (Brynbach FC1).

Another resident commented that: 
"If you know the area you're not that stupid to get on a bike and try and cycle around here, unless you take your bike somewhere like the Lake and you know you're safe" (Bryn Bach FG 2).

But others commented on the potential utility of the cycle lane, primarily for recreational cycling by expert bikers coming from other places. It also reportedly makes the journey by bicycle between Rassau and Garnlydan easier because it has a shallower gradient than the existing route along the Prince Philip road, which descends steep switch backs to cross the River Ebwy. However, in the 'after opening' focus groups local residents said that people don't use the cycleway because of its proximity to and alignment with the road, but that it had become a new dog-walking route for some people.

\section{Further emergent issues-regeneration, construction disruption and local community engagement}

Participants in the qualitative studies raised three important new social impacts arising from the project, which had not been included in original project appraisal: (i) regeneration effects, (ii) construction disruption to the road networks and surrounding communities; (iii) lack of involvement in the developer's community engagement process.

\section{Local regeneration benefits}

Most participants expressed hope that the road would encourage economic growth of the area by making journeys quicker and easier from Swansea to the Midlands. Rassau residents in particular hoped that the road would permit a rebirth of the Rassau and Tafarnaubach industrial estates, where local employers are facing a long-term decline in their businesses. Most participants felt that the road would not be sufficient to change this long-term trend, and additional measures are needed, such as public transport investments:

"That is one of the problems in the Valleys I mean you've got this Heads of the Valley Road up there and you might regenerate some of these estates but if you live down here and you're going to be working twelve hour shifts you can't rely on public transport so you need a car. Of course if you have been unemployed for a number of years, you probably can't afford a car".

There was also some scepticism about the ability of the road to create new jobs for local people without some direct government intervention. Some participants suggested there could actually be disbenefits to the local economy, as the road would create a 'by-pass' effect, thus, diminishing the numbers of drivers who would stop in the local communities to shop/visit/invest. On a more positive note, one citied potential for local regeneration was the proposed Circuit of Wales motor-racing track, which it was generally felt would not have come to the area without the new road:

"As a teacher in Ebbw Vale I say that to my kids on a regular basis as a bit of a motivation for them the fact is that we've got a possibility of a brand new racetrack on site, engineering, hospitality, a lot of high skilled jobs, language based, unless they step up a gear and actually want to actually succeed in school then 
those jobs are not going to be theirs, they'll be sweeping the track, they'll be picking up the rubbish”. \{Brynmawr School stakeholder interview, June 2015].

\section{Construction disruption}

Local residents reported they had experienced numerous road closures, route diversions and the impact of heavy plant movements on local roads over the 15-year construction period for the multiple A465 upgrade phases. In fact, many of them could not remember a time when they had lived without these problems. These negative social impacts of project construction are not currently included within the UK's social appraisal guidance, and so they are omitted from cost benefit analysis. Nevertheless, they are a significant social disbenefit for people living in the proximity of projects in many ways, often causing induced traffic on the local road network and housing market blight, as well as noise, dust and other health problems.

\section{Community engagement}

The Welsh Government regarded the community engagement work carried out by the constructor (Carillion) as 'above and beyond what would normally be the case in road construction projects'. Most participants reported a general satisfaction with the engagement process carried out by the constructor. However, some local residents, especially in the Waundeg community had low expectations of having their complaints heard by the constructors. This local resignation was towards several negative aspects of the road construction: for example noise, community severance, trip displacement and traffic disruption. Lower income households and some harder to reach groups had not been included in the developer's community engagement process, which tended to work through local councillors rather than directly with communities. The focus groups allowed these communities to more effectively communicate their concerns about the project to the Welsh Government, which then introduced some further mitigation measures to address some of their concerns. For example, a school bus has now been introduced to overcome the severance to the local primary school problems of Waundeg residents. This wider community engagement would have been even more effective for registering local needs and concerns if it had been conducted at the design stages of the project.

Overall, the qualitative interviews helped us understanding how whilst, as forecast, accessibility to long distance destinations increased after the opening of the new road (despite the Sect. 2 works reducing this effect quite dramatically), accessibility to local destinations decreased. Local accessiblity was further reduced whilst the old road was closed for detrunking generating increased traffic on local roads. Further insights from interviews, helped us understand how the prolonged road works made it hard for both locals and visitors to reach destinations when usual routes are diverted. At the same time, the issues with lack of other modes of transport made accessibility for those that do not own a car even more difficult. 


\section{Conclusions and recommendations}

In the light of growing public concerns about the impacts of transport infrastructures on the health and social wellbeing of local communities surrounding them, social assessment should be given much greater consideration in the business cases for proposed new transport projects early in the decision process. Social assessments are also needed to identify and, as far as possible, to mitigate or ameliorate any negative social outcomes projects might generate during the design process, during construction and at the operational stages. This helps to ensure that, everyone, but especially the most vulnerable members of society, are adequately protected from transport-related externalities that might undermine their health and social wellbeing. Giving space to local communities to tell their stories and views as part of the social assessment approach also helps to overcome some of the limitations of categorising 'hard to reach' or 'socially excluded groups' as unitary and fixed entities, uncovering the contextual, embodied and intersectional elements that constitute 'disadvantage'.

Currently, social assessments of transport projects are marginalised within economically dominated transport appraisal process within the UK, as in many other countries. Despite many excellent academic case studies and lengthy technical policy guidance documents, state-of-the art social assessments are rarely delivered in practice and are often side-lined within the overall project appraisal process.

Our case study to apply a mixed methods approach to the social assessment of a new major transport infrastructure project in Wales demonstrates how qualitative social research methods such as focus groups can uncover unintended consequences of projects that might be ignored in quantitative assessments. In undertaking this research for this study, we were able to identify some relevant practical constraints to the delivery of robust social assessments, for which we make some recommendations to more generally improve current practices and some condiserations for future research.

\section{Data availability for desk-based analysis}

The general lack of locally specific data for analysis is partly due to the type of data that is collected in public surveys, which is usually insufficiently fine-grained to identify microscale (individual- and community-scale) impacts. Many public datasets are also based on cross-sectional sample surveys, which cannot track individual changes in travel behaviours over time or in specific geographical locations and also do not record their travel preferences, perceptions of risk/safety, or their attitudes towards a given project or policy intervention.

Aggregate GIS analysis of the type used in TAG desk-based analysis is also unable to accurately assess exactly how different people will be affected by a project. The amplified and cumulative negative social impacts of a project on vulnerable and at risk groups in society (for example, children, older and disabled people, non-car owners, pedestrians and cyclists, etc.) is largely absent from such assessments. These groups are often under-represented in the quantitative survey-based datasets and can also be overlooked by the standard statutory consultation processes (Delbosc and Currie 2010). As such, these quantitative assessments can lead to an over emphasis on the 'strategic' benefits of projects (i.e. their aggregate journey-time savings for road users) to the detriment of more locally specific 
considerations of their sometime considerable burdens on local residents and the communities in which they are located.

These impacts are often seen as 'small' in comparison to the scheme as a whole and under a purely economic framework that values travel time savings more than health and wellbeing. As such, they do not necessarily affect the gross value of a project, but can nevertheless be a matter of extreme concern for local people living in close proximity to projects. This lack of integration between data analysis carried out for the CBA and other phases is a hindrance to effective SDI assessment. It would be useful if metrics extracted during transport modelling runs included indicators useful for SDI assessment, particularly local level changes in demand, routing, destination and mode amongst the populations in our study area. As most transport modelling is carried out by external consultants and not local authorities, this should be in model specifications at the outset of the appraisal process. The problem largely is not what these models can and cannot do in terms of their computational powers, but that important social questions are rarely asked of them because they are engineering or economically focused rather than social policy driven.

Using more straightforward GIS-based tools and complimentary public datasets is useful to provide a baseline and a descriptive context at the scoping stage. GIS tools designed specifically as scoping indicators have some value if used early in the appraisal process to identify where local level issues may exist (e.g. Philips et al 2020). However, this is no substitute for understanding exactly how local people will be socially impacted by the project, which can only be revealed through local data collection surveys and community engagement exercises. For example, it is possible to map changes in air pollution at the level of receptors (i.e. houses, schools, hospitals, old people's homes), but this doesn't effectively identify how many people are affected at each receptor or identify whether they might be more vulnerable to particular irritants e.g. children, older people and people with longterm associated illnesses. Nor does the quantitative data show the wider impacts in terms of perception of safety, perception of changes in life quality and similar, that could anyway be detrimental to citizens' wellbeing.

\section{Assessment of distributional impacts}

All projects will have 'winners' and 'losers'. However, a well-implemented distributional analysis aims to pinpoint precisely who the winners and losers are. This can help determine whether the distributional impacts of a project are equitably distributed in terms of both their benefits and burdens. In this way, their social benefits can be extended, and burdens more effectively mitigated in the early stages of the design process (e.g. at the option appraisal and design stages of the project). It is also worth noting that mitigation at the design stage may be more cost effective than post project remedial works. Effective social appraisal needs to be properly applied at each stage of the appraisal process, and additional surveys will be needed, so this should be included in project costing from the outset.

The way that distributional impacts are aggregated in appraisal also needs careful thought. The distributional impacts of projects are both spatially and socially specific, i.e. different places and people will be affected differently. Ultimately, no transport engineer, planner or policymaker purposefully wishes to put people's lives or livelihoods at risk through their professional actions. Social assessments are there to help prevent reduced quality of life and social exclusion as unintended or unrealised consequences of transport project investments. Our paper illustrates that one way to enhance this process is to engage all the social actors from the first phases of project design through to delivery and 
evaluation. While such an approach might have its drawbacks from a cost and management perspective, it can help to save time and money on retrofits at later stages of the delivery process. SDI assessments can also facilitate stakeholder ownership of projects and thus gain greater public acceptability. They also help to ensure that incremental social benefits are better locally targeted and potentially vulnerable populations are protected from the social burdens associated with the transport system.

Acknowledgements The authors would like to thank Louise Reardon and Diana Talverie for their invaluable assistance with delivery of the local case study research, with data transcriptions and to John Nellthorp and James Laird for their inputs to early development of the case study methodology and the Carillion Local Engagement Officer. Our thanks also go to the project officers at the Welsh Government who recognised the value of conducting an SDI appraisal even though this was not a statutory requirement for the A465 project, and for their willingness to share their data, knowledge and experience in the research process, and to listen and positively respond to the study findings. We would also like to thank the local residents who particpated in our research study for their frank and honest views.

Open Access This article is licensed under a Creative Commons Attribution 4.0 International License, which permits use, sharing, adaptation, distribution and reproduction in any medium or format, as long as you give appropriate credit to the original author(s) and the source, provide a link to the Creative Commons licence, and indicate if changes were made. The images or other third party material in this article are included in the article's Creative Commons licence, unless indicated otherwise in a credit line to the material. If material is not included in the article's Creative Commons licence and your intended use is not permitted by statutory regulation or exceeds the permitted use, you will need to obtain permission directly from the copyright holder. To view a copy of this licence, visit http://creativecommons.org/licenses/by/4.0/.

\section{References}

Aledo-Tur, A., Domínguez-Gómez, J.A.: Social Impact Assessment (SIA) from a multidimensional paradigmatic perspective: challenges and opportunities. J. Environ. Manage. 195, 56-61 (2017). https://doi. org/10.1016/j.jenvman.2016.10.060

Antonson, H., Levin, L.: A crack in the Swedish welfare façade? A review of assessing social impacts in transport infrastructure planning. Progress Plan. (2018). https://doi.org/10.1016/j.progress.2018.11.001

Barrow, C.: Social impact assessment: an introduction arnold. Oxford University Press, Oxford (2000)

Davies, N., Atkins, G., Slade, D.: How to transform infrastructure decision making in the UK. Institute for Government, London (2018)

Delbosc, A., Currie, G.:Designing inclusive transport surveys: sampling disadvantaged people' Paper delivered at the 33rd Australasian Transport Research Forum Conference held in Canberra, on 29 September 1 October, 2010 (2010)

Department for Transport Transport Analysis Guidance https://assets.publishing.service.gov.uk/gover nment/uploads/system/uploads/attachment_data/file/712965/webtag-transport-appraisal-processmay-2018.pdf Last accessed 24.05.19 (2018)

Fell, M., Pye, S. Hamilton, I.: Capturing the distributional impacts of long-term low-carbon transitions. Energy Innovation and Societal Transitions (In Press http://dx.doi.org/https://doi.org/10.1016/j. eist.2019.01.007) (2019)

Flyvbjerg, B.: What you should know about megaprojects and why: an overview. Proj. Manage. J. 45, 6-19 (2014). https://doi.org/10.1002/pmj.21409

Geurs, K.T., Krizek, K.J., Reggiani, A. (eds.): Accessibility analysis and transport planning: challenges for Europe and North America. Edward Elgar Pub, Cheltenham, Northampton, MA (2012)

Golub, A., Martens, K.: Using principles of justice to assess the modal equity of regional transportation plans. J. Transp. Geogr. 41, 10-20 (2014). https://doi.org/10.1016/j.jtrangeo.2014.07.014

Grengs, J.: The abandoned social goals of public transit in the neoliberal city of the USA. City 9, 51-66 (2005). https://doi.org/10.1080/13604810500050161

Guhnemamm, A., Laird, J.J., Pearman, A.: Combining cost-benefit and multi-criteria analysis to prioritise a national road infrastructure programme. J. Transp. Policy 23, 15-24 (2012)

Guzman, L.A., Oviedo, D.: Accessibility, affordability and equity: assessing 'pro-poor' public transport subsidies in Bogotá. Transp. Policy 68, 37-51 (2018). https://doi.org/10.1016/j.tranpol.2018.04.012 
He, G., Mol, A.P.J., Zhang, L., Lu, Y.: Environmental risks of high-speed railway in China: public participation, perception and trust. Environ. Dev. 14, 37-52 (2015). https://doi.org/10.1016/j.envde v.2015.02.002

Lucas, K.: Running on empty: transport, social exclusion and environmental justice. Policy Press, Bristol (2004)

Lucas, K.: Transport and social exclusion: Where are we now? Transp. Policy 20, 105-113 (2012). https ://doi.org/10.1016/j.tranpol.2012.01.013

Lucas, K., Pangbourne, K.: Assessing the equity of carbon mitigation policies for transport in Scotland. Case Stud. Transp. Policy 2, 70-80 (2014). https://doi.org/10.1016/j.cstp.2014.05.003

Lucas, K., van Wee, B., Maat, K.: A method to evaluate equitable accessibility: combining ethical theories and accessibility-based approaches. Transportation 43, 473-490 (2016). https://doi. org/10.1007/s11116-015-9585-2

Markovich, J., Lucas, K.: The social and distributional impacts of transport: a literature review, In: Working Paper. Transport studies unit (2011)

Mottee, L.K., Howitt, R.: Follow-up and social impact assessment (SIA) in urban transport-infrastructure projects: insights from the parramatta rail link. Aust. Plan. 55, 46-56 (2018). https://doi. org/10.1080/07293682.2018.1506496

Mottee, L.K., Arts, J., Vanclay, F., Miller, F., Howitt, R.: Reflecting on how social impacts are considered in transport infrastructure project planning: looking beyond the claimed success of sydney's South West rail link. Urban Policy Res. (2020). https://doi.org/10.1080/08111146.2020.1730787

Shropshire Council Commissioning Support Social Value Information Pack https://www.shropshire.gov. uk/media/3783/social-value-information-pack.pdf last accessed 24.04.19s (2015)

Philips, I., Walmsley, A., Anable, J.: A scoping indicator identifying potential impacts of all-inclusive MaaS taxis on other modes in Manchester. Transp. Find. (2020). https://doi.org/10.32866 /001c. 11524

Northern Powerhouse (2019) Connectivity and Transport webpage https://northernpowerhouse.gov.uk/ connectivity-and-transport/. Last accessed 24.04.19

Schwanen, T., Lucas, K., Akyelken, N., CisternasSolsona, D., Carrasco, J.-A., Neutens, T.: Rethinking the links between social exclusion and transport disadvantage through the lens of social capital. Transp. Res. Part A Policy Pract. 74, 123-135 (2015). https://doi.org/10.1016/j.tra.2015.02.012

Sheller, M.: Verso. Mobility Justice, Brooklyn, NY (2018)

Simpson, E.: An anthropologist among the transport specialists: Social science insights on the politicaleconomy barriers to the implementation of low-carbon transport in urban South Asia and Africa. Department for International Development, London (2018)

Transport for London: Valuing the health benefits of transport schemes: guidance for London. Transport for London (2015)

VanclayEstevesAucampResearchFranks, F.A.M.I.E.D.M.: Social impact assessment: guidance for assessing and managing the social impacts of projects. International Association for Impact Assessment, Fargo, ND (2015)

Verlinghieri, E., Schwanen, T.: Transport and mobility justice: evolving discussions. J. Transp. Geogr. 87, 102798 (2020). https://doi.org/10.1016/j.jtrangeo.2020.102798

Walker, G.: Environmental justice, impact assessment and the politics of knowledge: the implications of assessing the social distribution of environmental outcomes. Environ. Impact Assess. Rev. 30, 312318 (2010). https://doi.org/10.1016/j.eiar.2010.04.005

Welsh Government (2012) A465 DUALLING SECTION 3 BRYNMAWR TO TREDEGAR Traffic Forecasting Report Supplement Arup Document reference 12-8331 Traffic Forecasting Report Supplement

Welsh Government (2017) Welsh Transport Appraisal Guidance WelTAG 2017 https://gov.wales/sites/defau 1t/files/publications/2017-12/welsh-transport-appraisal-guidance.pdf

Wong, C., Baker, M., Webb, B., Hinks, S., Schulze-Baing, A.: Mapping policies and programmes: the use of GIS to communicate spatial relationships in England. Environ. Plan. B Plan. Design 42, 1020-1039 (2015)

Publisher's Note Springer Nature remains neutral with regard to jurisdictional claims in published maps and institutional affiliations. 